\title{
OMNIITOX - Operational Life-Cycle Impact Assessment Models and Information Tools for Practitioners
}

\author{
Sverker Molander ${ }^{1 *}$, Peter Lidholm², Diederik Schowanek ${ }^{3}$, Mar Recasens ${ }^{4}$, Pere Fullana i Palmer ${ }^{5}$, \\ Frans M. Christensen ${ }^{6}$, Jeroen B. Guinée ${ }^{7}$, Michael Hauschild ${ }^{8}$, Olivier Jolliet ${ }^{9}$, Raul Carlson ${ }^{10}$, \\ David W. Pennington' ${ }^{9}$ and Till M. Bachmann ${ }^{11}$ \\ 1 Environmental Systems Analysis, Chalmers University of Technology, SE 41296 Göteborg, Sweden \\ 2 Volvo Technology Corporation, Göteborg, Sweden \\ 3 Procter \& Gamble Eurocor, Strombeek-Bever, Belgium \\ 4 Antonio Puig S.A., Barcelona, Spain \\ 5 Randa Group, Cardenal Vives i Tutó, Barcelona, Spain \\ 6 European Commission, Joint Research Centre, Institute for Health and Consumer Protection, European Chemicals Bureau, TP 582 , \\ Via E. Fermi 1, I-21020 Ispra (VA), Italy \\ 7 Institute of Environmental Sciences (CML), Leiden University, P.O. Box 9518, 2300 RA Leiden, The Netherlands \\ 8 Department of Manufacturing Engineering and Management, Technical University of Denmark (DTU), Building 424, \\ DK-2800 Lyngby, Denmark \\ 9 Industrial Ecology - Life Cycle Systems, GECOS, Swiss Federal Institute of Technology Lausanne (EPFL), CH-1015 Lausanne, \\ Switzerland \\ ${ }^{10}$ Industrial Environmental Informatics, Chalmers University of Technology, SE-412 96, Göteborg, Sweden \\ ${ }^{11}$ Institute of Energy Economics and the Rational Use of Energy (IER), University of Stuttgart, Heßbrühlstraße 49a, \\ D-70565 Stuttgart, Germany
}

* Corresponding author (sverker.molander@esa.chalmers.se)

\section{DOI: http://dx.doi.org/10.1065/lca2004.08.167}

\section{Abstract}

This article is the preamble to a set of articles describing initial results from an on-going European Commission funded, 5th Framework project called OMNIITOX, Operational Models aNd Information tools for Industrial applications of eco/TOXicological impact assessments. The different parts of this case study-driven project are briefly presented and put in relation to the aims of contributing to an operational life cycle-impact assessment (LCIA) model for impacts of toxicants. The present situation has been characterised by methodological difficulties, both regarding choice of the characterisation model(s) and limited input data on chemical properties, which often has resulted in the omission of toxicants from the LCIA, or at best focus on well characterised chemicals. The project addresses both problems and integrates models, as well as data, in an information system - the OMNIITOX IS. There is also a need for clarification of the relations between the (environmental) risk assessments of toxicants and LCIA, in addition to investigating the feasibility of introducing LCA into European chemicals legislation, tasks that also were addressed in the project.

Keywords: Case studies; characterisation factor; chemicals; environmental risk assessment; hazard assessment; information system; life cycle impact assessment (LCIA); potentially toxic substances; regulation; risk assessment; risk ranking

\section{Introduction}

LCA is now recognized as a valuable tool for comprehensive environmental assessment of products and processes. Over the last decade, it has received much attention, which among other important steps has led to an international standardization of the LCA procedure (ISO 1997, 1998, 2000, 2002).
The general conceptual idea of LCA has also been accepted as a basis for governmental activities within the European Union, where one of the latest milestones is the European Commission's communication on Integrated Product Policy, IPP (CEC 2003a), which is founded on life-cycle thinking.

The LCA method development has encompassed various specific steps that include the inventory analysis (ISO 1998), different aspects of impact assessment (ISO 2000) and arrangements of data handling (ISO 2002). Traditionally, and due to the needs for simplifications driven by practical constraints, LCA studies have focused on the environmental impact of the larger material flows, like resource uses and large emissions of greenhouse gases and nitrogen oxides, for instance. The toxicity impact categories, however, are in many cases more or less overlooked in LCAs, despite the existence of early (e.g. BUS 1984, BUWAL 1990) and more recent (e.g. Hauschild \& Wenzel 1998, Guinée et al. 2002, Udo de Haes et al. 2002) methodological attempts to deal with these impact categories. This is partly due to the fact that the coverage of the numerous smaller, but potentially significant, material flows challenge the LCA procedure, both in the inventory step and in the impact assessment step. In addition, many LCIA indicators for toxic impacts are not related to risks or actual impacts (ISO 14042, 2000).

In the LCI, more work is needed in order to gather data with a higher resolution, both in terms of the flow of chemicals in and across product systems, as well as in terms of the emission of chemicals from the various processes within a life cycle's boundaries. An aggravating aspect of the problem is that for these often small mass flows per functional unit, it is usually not possible to rely on existing generalized data, as is possible for carbon dioxide or sulphur dioxide, 
for example, which are examples of substances with big mass flows. Such data often stem from information on energy conversions, and therefore inventory data for small flows of substances not related to energy conversions often need to be gathered specifically for the product or process investigated. As a consequence of the requirement of more work, which equals higher costs, the toxicity impact categories are often left out from LCA studies, a fact that strongly reduces the relevance of the LCA results for many types of products. The intention to establish inventory data on toxic emissions is also not encouraged by the problems faced in the impact assessment step.

The LCIA aspects related to substances with small material flows per functional unit concern many different issues. In general, impacts of toxicants, either on humans or the environment, often occur on a more local scale due to the exposure-response relationships operating when toxicants cause effects on humans (see e.g. Aldridge 1996) and ecosystems (see e.g. Newman 1998, Levin et al. 1989), while 'global impacts' have been the concern of the other LCIA impact categories, such as, for example, impacts on global warming caused by green house gases or on the ozone layer caused by CFCs (see e.g. Hauschild \& Wenzel 1998, Guinée et al. 2002). This scale dependency connects to several methodological difficulties, such as

- the defining of appropriate impact sub-categories within the toxicity impact categories (see e.g. Hauschild \& Wenzel 1998),

- the on-going debate where along the cause-impact chain to stop modelling - mid-point or end-point (see e.g. Hertwich \& Hammitt 2001, Bare et al. 2002), and

- the level of detail in modelling (see e.g. Allen $\&$ Hoekstra 1992, Peterson \& Parker 1998).

The absence of characterisation factors to cover more than a small fraction of substances occurring in life-cycle assessments of ordinary products reflects another important issue, namely the lack of easily available substance data for the construction of characterisation factors for the emissions of many different substances in small amounts occurring in some LCAs (as well as in other types of related assessments).

The OMNIITOX project was designed in order to contribute to a 'filling of this gap', tackling the LCIA problems from many sides simultaneously, and together with users creating solutions in order to answer questions, clarify concepts, and ending up with operational models for LCIA of toxicants. It is highly acknowledged that complementary activities are also needed in order to fill gaps in LCI and other areas of LCIA.

This article is a preamble to a set of articles that present various initial results from the on-going work in the OMNIITOX project and describes the guiding ideas of OMNIITOX, which attempts to contribute to a resolution of the exigent problematics regarding inclusion of impacts by smaller material flows in LCA. OMNIITOX is a European Commission funded, 5th Research Framework project ${ }^{1}$ aiming at the enhancement of models and information tools necessary

\footnotetext{
1 Funding for projects within the Research Framework programmes does not
} imply any endorsement, or obligation, from the European Commission. for assessment of potentially hazardous substances within LCA. The project is a case study-driven approach, where method comparison and development go hand in hand with the application of LCA by practitioners in industry.

\section{Problem refinement}

The OMNIITOX consortium - a group of five companies (Antonio Puig S.A., Procter \& Gamble, Randa Group, Stora Enso and Volvo), five academic research institutions (Chalmers University of Technology, Danish University of Technology, Leiden University, Stuttgart University and Swiss Federal Institute of Technology) and a regulatory body (the European Chemicals Bureau of the Directorate General Joint Research Centre) initially defined the problems entirely within the OMNIITOX consortium, based on experiences and perceptions held by a limited set of practitioners and academic method developers. However, in order to refine the problem perception, four sector workshops were performed. The industrial and governmental partners of the consortium, representing a variety of industrial sectors as well as one governmental institute, arranged these workshops. Their output was assessed by Molander (2002) and the outcome of the workshops displayed a wide range of perceptions, problems, needs, suggestions, recommendations and preferences with regard to the use of LCIA and (environmental) risk assessment ((E)RA) methods. The statements from the workshops were grouped and analysed. The groups that were identified were 'methods and their use', 'data and information', and 'competence and communication'. Some general conclusions were reached despite the very diverse background of the workshop participants and the different needs expressed.

Regarding methods and their use, many questions were related to choice and use of methods, as well as to their application domains. There was also an expressed wish for development of further particular capabilities, such as methods for more site-specific and substance-class specific (e.g. inorganics) LCIAs. There was also a clear message for developing easy-to-use and simplified methods, including the fact that such methods should reach a level of refinement and consensus so they can be regarded as some sort of basis for an international agreement regarding methods used in the field.

The conclusions with respect to data and information were mostly related to data availability (Molander 2002), particularly with regard to the rather long list of properties/ characteristics of a specific chemical substance, that can be considered for the construction of a characterisation factor, as well as the availability of characterisation factors for a high number of substances that are not released in large quantities or of high concern (many thousands). The task is rendered more difficult since data quality issues are linked to the problems of quantity (Guinée et al. 2004). The workshop participants deemed integration of these issues into an information system important and at least partly feasible. Regarding competence and communication, further education and training was sought focusing on information on the similarities and differences of the LCA methods with risk assessment approaches and their use. 
In addition to direct outcomes of the workshops, it was observed that the representatives from the various sectors expressed quite different opinions. This might be related to the fact that the sectors represented in OMNITOX have quite different roles in the production chains (cosmetics, laundry detergents and consumer products, pulp and paper products and automotives, respectively), as well as in the context of chemical regulation, therefore having different views and preferences regarding the methods. The differences between the industrial sectors were also reflected by the way the different workshops were planned and performed by the different workshop teams, e.g. the programmes and formats differed between the workshops, as did the choice of problem focus.

Based on the conclusions from the sector workshops, a refined general problem definition was formulated for the project, focusing on - without contradiction - some of the aspects of the original objectives: the OMNIITOX-project is aiming at development of simplified, operational models for characterisation of toxic impacts for a large number of substances, recognizing the limited availability of data for chemical properties that are available. The models are to be implemented in a web-based information system to facilitate data availability and model calculations, while providing guidance on the use of LCIA and (E)RA.

\section{Case Studies as a Basis for Methodological Developments}

The general approach of OMNIITOX is to base the development of characterisation methods on experiences made in real world LCA case studies and to adopt insights from existing characterisation approaches. In this way, characterisation methods can be further tuned to the needs of users and to better account for the data that are commonly available within industry (usually in response to regulatory requirements, as well as additional consumer/worker-protection initiatives). It also gave the opportunity to collect data for a number of industry specific substances that can be used for comparison with existing, and for the development of new, characterisation methods. Future users of the information system are in this way involved in all steps of the development; from the problem refinement to the design and implementation of the information system.

The five case studies are performed by the four partner companies (Volvo, Procter \& Gamble, Stora Enso, and Antonio Puig S.A.) and by a body within the European Commission (the European Chemicals Bureau of the Directorate General Joint Research Centre). The studies were formulated by the project partners in order to meet their own needs and interests, but in collaboration with their sector industries in order to be able to gather important aspects of interest to the particular sector. Since the partners represent different branches, with different experiences, needs, and expectations, there is a fair chance to cover many different problems with regard to LCAs incorporation of the toxicity impact categories, and to have various viewpoints on the development of methods and the information system. The case studies therefore offer a possibility for coordinated learning by the directly involved organisations, for sharing experiences with other companies and for contributing to the production of, hopefully, lasting results that can be used both within and outside the partner organisations.

The case study performed by the Volvo group, a vehicle manufacturing company, concerns LCA and ERA of lightweight materials as substitutions for metals (Lidholm et al. 2002). Components of different material types were compared in an extensive LCA-study, which was complemented with an (E)RA based on classification information of hazardous substances. The LCA compared the potential environmental impacts attributable to a conventional Volvo 5000 city bus body, with two different lightweight concepts. The main difference was the core material used in the composite sandwiches.

The results of the conventional LCA suggested, for all three LCIA methods used (EPS (Steen, 1999) EDIP (Hauschild \& Wenzel 1998) and EcoIndicator 99 (Goedkoop \& Spriensma 1999)), that the potential environmental impact for the light weight concepts are $10-15 \%$ lower than the conventional concept. The dominating stage of the life cycle is the use phase, which represents more than $95 \%$ of the total impact for all of the concepts. This demonstrates, for example, the importance of lowering the fuel consumption by reducing the weight of the bus.

However, an important observation of the study indicates the necessity to improve the LCI. In conventional LCIs, many substances are aggregated into groups like e.g. 'VOC' or 'metals'. Using existing characterisation factors on a conventional LCI, impacts of these groups of substances are generally not included or are considered with high default values, since the construction of characterisation factors requires the identification of individual substances. In order to perform the characterisation, the substance composition of these 'clustered emissions' was further specified. After disaggregating the clusters into specific substances for which characterisation factors were applicable, a somewhat different result appeared. For some of the different existing characterisation methods applied in the LCIA, the production stage dominated the potential environmental impacts for the (eco)toxicity categories, while the use stage was totally dominating the results from the impact assessment in the conventional LCA with aggregated VOC emissions. This study demonstrated the inadequacy of ordinary LCI methods and LCI databases when impact assessment of toxicants might be of importance. The study also demonstrated that LCIA and ERA can give somewhat different results.

The case study performed by Procter \& Gamble (Pant et al. 2004 ) is comprised of LCA and ERA studies of laundry detergents to compare their ecotoxic impact on the aquatic environment. Three product forms, a Regular Powder, a Compact Powder and a Compact Liquid, were investigated. To enable a comparison of the ERA (based on the EU Ecolabel approach for detergents (CEC 1999) and EUSES (CEC 1996), a software performing calculations based on the Technical Guidance Document (TGD) of the EU on Environmental Risk Assessment (ERA) of chemicals (CEC 2003b), with different LCIA methods for aquatic ecotoxicity (Impact 2002 (Jolliet et al. 2004), USES-LCA (Huijbregts 1999) and UMIP-EDIP methods (Hauschild \& Wenzel 1998)), consistency in the technical design between the ERA 
and the LCA was a key prerequisite, e.g. by defining the system boundaries for the ERA and the LCA in a comparable way and by calculating the characterisation factors in the LCIA and the PEC/PNEC ratios in the ERA based on the same data set. During the data collection from internal databases and various external databases, problems regarding data scarcity and consistency were encountered for some physico-chemical parameters needed for the construction of characterisation factors. Such data were typically better covered for high-volume than for low volume chemicals.

Significant differences between the LCIA methods applied with respect to data needs and results were identified. The LCIA methods for freshwater ecotoxicity and the ERA see the Compact Powder slightly better than or equal to the Regular Powder, followed by a clear third formulation. The Compact Liquid. Impact 2002 for freshwater and USES LCA for marine water show a very different picture, suggesting Compact Liquid as the clear winner over Compact Powder with Regular Powder being the least favourable option. Even the LCIA methods, which resulted in the same product ranking, e.g. EDIP chronic aquatic ecotoxicity and USES-LCA freshwater ecotoxicity, differed significantly in most contributing substances. The difference in the results is likely to be due to a different approach to the modelling of fate and exposure resulting in deviating assumptions on the residence time of substances in freshwater. The situation that different LCIA methods might come up with different answers to the question 'which detergent type is to be preferred?' is not satisfactory and required further investigation. This can hamper practical decision support, as LCA practitioners usually will not be in a position to choose a LCIA method for their specific case, since different methods applicable for LCIA have different limitations and advantages depending on their different design criteria and field of application. The detergent case study provides further evidence for the need to develop a practical method, which finds common ground regarding fate, exposure and effect modelling to overcome the current situation of diverging results.

The case study of Stora Enso, comprises an LCA of pulp and paper production at three Stora Enso pulp mill sites in Sweden. These represent integrated and non-integrated paper production and different types of aquatic recipients. The LCA was a 'cradle to gate' study at a screening level, complemented by a separate assessment of the human toxicity and site-specific ecotoxicity impacts. Since local variability between recipients is a key factor for the pulp and paper sector, the development of site-specific approaches for LCIA has been one of the main issues of this case study. The relatively high amount of hazardous waste indicates that ecotoxicity and human toxicity may be of importance. The 'non-toxic 'results of the study are very sensitive to the choice of energy scenarios, such as site dependent energy versus energy from the most sensitive (marginal) supplier. Site dependent Swedish electricity is used as the main scenario, where electricity is used but calculation was made of marginal electricity produced from natural gas showing increased environmental impacts as well as a decreased amount of nuclear waste. It was also found that differences between sites in the size of the recipient water volumes was more important than dif- ferences in the discharged quantities in determining the outcome of a comparison between the sites regarding potential environmental effects. This result suggests that a site-specific approach may be relevant for selected processes in the life cycle and that further development is necessary.

The objectives of the case study performed by Antonio Puig SA and the Randa Group (an environmental consultancy), were to compare LCA results on three cosmetic products using different (eco)toxicity impact models, to compare LCA and (E)RA with other tools currently used, to propose alternatives to merge or complement both types of methods in a non-contradictory way, and to evaluate the possibility to introduce (E)RA and LCA as evaluation tools within the Puig company. The results of the (E)RA indicated, as in the Procter \& Gamble case study, that there was not sufficient data available, e.g. for chronic human toxicity needed for the construction of characterisation factors.

Using a risk assessment software (Simple Treat 3.0) only two substances of the shower gel investigated showed an unacceptable risk for the aquatic compartment. Using the EUSES 1.00 software (CEC 1996) and running a regional scenario, no unacceptable risk from any substance in any compartment was similarly observed. The LCA focused on the chemical ingredients contained in the products under study and aimed at evaluating the impacts, irrespective of what is considered acceptable or not, over their entire life cycle, paying special attention to the (eco)toxicity impacts. The (eco)toxicity impacts were evaluated only in the use phase/end of the life cycle, where the chemicals actually contained in the cosmetics are emitted to the environment.

The case study being performed by the European Chemicals Bureau, is part of a feasibility study of the potential application of elements from the LCA framework in the chemical regulatory work at the European Union level. The study is briefly described below and findings are detailed in Christensen $\&$ Olsen (2004). The case study included results from a regulatory-orientated RA and an LCA of compounds in metal working fluids (MWFs). The RA comprised of a study of short and medium-chain chlorinated paraffins (SCCP and MCCP). The RA part of the case study illustrated the EU risk assessment scheme (CEC 2003b) and is a basis for comparison with an LCA approach for the same substances. SCCP and MCCP are chemically similar and the risk assessments have shown that this is also the case for their applications and properties. Consequently, these regulatory risk assessments end up with comparable conclusions as to where the substances pose risks and where risk reduction measures should be taken.

The LCA focused on a comparison between an extreme pressure metal working fluid (MWF) containing MCCP and an alternative MWF containing sulphurised compounds. The results of the impact assessment suggested that there are only minor differences between the two alternative systems. The differences are due to a slightly larger use of energy and steel in the production of tubes when using the non-chlorinated alternative to MCCP based MWF, i.e. a slightly lower environmental impact from the MCCP containing MWF. It might be concluded that the small differences between the two systems studied cannot be interpreted as significant. 
Regarding the substitution of chemicals in MWFs, where chlorinated paraffins are important constituents, it has been found that they cannot be modified by simple substitution of MCCP on a 'substance-for-substance' basis. Therefore, an important conclusion is that RAs comparing alternatives cannot only consider the substance level. It is necessary to take the function that the substances contribute in the chemical product into account, and to widen the scope of the risk assessment. Interestingly, this is the default approach in LCAs, in which the functional unit is the basis for comparisons. These results, however, are hampered by the difficulties in obtaining reliable and comprehensive inventory data. This finding suggests that, where relevant, an authoritative body should rather conduct such assessments, e.g. a sector or branch research institute that might be able to provide data based on studies performed within industry. This, along with other issues related to potential application of LCA in the chemical regulatory framework, are further discussed in Christensen \& Olsen (2004) and in section 5 of this article.

\section{Relations between (E)RA and LC(I)A}

It is not always clear which is the more adequate method to apply in a particular situation when assessing the environmental performance of (chemical) products. The two approaches for quantifying potential effects on human health and the environment use two different starting points. LCIA is a part of LCA, which models the potential impacts related to the provision of a product or service as expressed in the 'functional unit' of the technical system under study, while (E)RA, at least according to European methods (CEC 2003b), is assessing whether 'unacceptable' risks exist related to emissions mainly of single substances at local or regional scales. From these two different, albeit complementary perspectives, both methods make statements about the potential or probability of effects. Moreover, different, and even contradictory results may occur as, for instance, found in a study by Saouter \& Feijtel (2000) applying LCA and ERA. These differences need to be understood, explained and methods eventually improved to overcome any unnecessary differences.

A clarification and guidance is needed about how to discriminate between the methods and even when and how to use the appropriate one, since considerable confusion among some practitioners exists. The question is somewhat more complicated than what may intuitively be considered, since both LCA and (E)RA are system methods that can, and should, be adjustable to the specific situation and the specific questions at hand in a particular case. The flexibility of the methods creates a need for guidance regarding several of the theoretical and practical aspects, such as the choice of system boundaries or the choice to include, or not include, sub-systems or impact categories in the study. There are clearly lessons to be learnt regarding the matching of questions to methods, since e.g. the choice of system boundaries (for both methods) or functional unit (LCA) influence the result and should also be matched to the question and system investigated.

Another difference between some methods is that (E)RA mostly intends to provide conservative estimates of toxicity for screening (e.g. the 'reasonable worst case-approach', CEC 2003b), while the needed toxicity indicator of LCIA should provide a 'comparative median toxicity indicator', without bias on the conservative side (that is overestimating toxicity). This is a common difference between risk assessments intended for screening and assessments that provide comparative insights.

The comparison of (E)RA and LCIA was identified as an important part of the OMNIITOX project from the start. The Procter \& Gamble case study (parts of it being presented by Pant et al. 2004) is focused on this comparison. Similarities and differences, as well as the possibility to relate the two approaches to each other are also under investigation in other parts of the OMNIITOX project, among others is an in-depth analysis of results from the case studies performed. The feasibility study performed also looks into relations between (E)RA and LCA beyond the toxicity impact category (see section 5 and Christensen \& Olsen 2004).

\section{Requirements on Operational Models for LCIA of Toxicants: Model comparison and development}

The OMNIITOX-project has included extensive comparisons of existing models in order to meet requirements on operability, stability and acceptance. These studies covered both socalled selection methods (Larsen et al. 2004) as well as more advanced characterisation methods such as IMPACT 2002, CalTOX, USES-LCA, and EDIP97, that will be presented in a future paper (Rosenbaum et al. in prep.). The comparisons regarding the selection methods have covered both general descriptions of the methods, their relations to chemical ranking and scoring methods (e.g. Davis et al. 1997) and differences in their performance when applied in LCA. The comparisons have been based on data from the case studies and data from a selected test set of substances that were assembled using representative substances to reflect the plausible range of different potential combinations of chemical and physical properties.

Besides the scientific analysis and acceptability of the LCIA methods, the further requirements on operational models relate to their usability. Participants in the automotive workshop requested a 'best practice method'. Such a method should be practical, easy to use and flexible (meaning a method with different levels of 'resolution' or 'grain'). Among the many aspects of the vaguely defined 'usability' are also reliability, transparency, and time consumption for performing the assessment. The wish list is somewhat contradictory and probably reflects the various contexts where LCA is used and the different skills/experiences are held by different users (Molander 2002). The comparisons mentioned above have also tried to cover some of these user aspects, including interaction with the industry and government partners, but without extensive user studies.

The requirements on operational models also include their ability to be applicable to a very wide variety of substances. Since very many substances can be expected to occur in life cycle inventories and many methods exist that focus on wellstudied chemicals, the refined aim of the project focused on the possibility to construct characterisation factors for the large number of substances where data are generally lacking. This was supported by experiences from the case studies, where it was sometimes difficult to provide sufficient data to assess all emissions. However, trying to cover many chemical substances places high demands on data availabil- 
ity, which is a well-known restriction when dealing with chemical risk assessments (Allanou et al. 1999).

The model development strategy chosen for the OMNIITOXproject (Guinée et al. 2004) recognises these data availability issues and suggests a pragmatic dual model approach, with one less data-demanding model and a more data-demanding, more sophisticated, model for the calculation of compatible characterisation factors. Making available characterisation factors for very many substances is not only a matter of finding data on properties, but also a matter of developing a characterisation model appropriate to the data that is available.

\section{Feasibility of LCA for Chemicals Regulation}

The current European legislation for chemicals (see e.g. Council Directive 67/548/EEC and amendments, especially Council Directive 92/32/EEC) focuses on single substances, their inherent properties and potential effects on human health and environment related to emissions of, and exposure to, a particular substance. However, the ordinary risk assessment procedure, as covered by Commission Regulation (EC) 1488/94 and Commission Directive 93/67/EEC, and detailed in the Technical Guidance Document (CEC 2003b), leaves out other non-toxicity impact categories like those covered by LCA. Hence, under particular circumstances (e.g. when assessing various risk management options, comparing substances and dealing with substances that are subject of specific deeper investigations) the use of LCA can be an attractive opportunity for complementing the extensive (E)RAs. This issue is further highlighted in Christensen \& Olsen (2004) along with an investigation of other potential interactions between the methodologies, e.g. exchanging methodological elements and data between regulatory (E)RA and LCA.

Presently, the European chemicals policy is under revision following the Commission white paper (CEC 2001). Upcoming legislation, such as the REACH regulation (Registration, Evaluation and Authorisation of Chemicals), contains some elements of LCA pointing to the possibility of a future role for LCA in chemical regulation.

In order to investigate the feasibility of including LCA in the regulatory framework, a specific study covering these issues was initiated and performed by the JRC's European Chemicals Bureau (ECB). This feasibility study, further described by Christensen \& Olsen (2004) includes various aspects such as stakeholders' opinions, methodology (data acquisition, time consumption, modelling short cuts, etc.) and the relation to legislation. With this approach, the OMNIITOX project broadens the scope of the methodological development to assess the feasibility to further institutionalise the use of LCA.

\section{Information system for the Facilitation of LCIA of Toxicants}

As pointed out above, industrial users request models that are easy to use and give reliable results at a modest investment of time and skill. The integration of various functions needed for an efficient LCIA of toxicants into a web-based information system is one of the important aims of the OMNIITOX project that contributes to making the LCIA- model operational and user-friendly? There are several reasons for the construction of such an information system. One of them is the considerable time and expertise needed for new data gathering when using existing models. Functions of the information system therefore include enhanced data availability, the storage of the models and their documentation, together with the constructed characterisation factors and help for practitioners regarding choice of approaches and interpretation of results.

Necessary prerequisites for the information system, such as the conceptual model and data quality foundations, are described in the adjoining papers by Carlson et al. (2004) and Erixon et al. (2004). The system architecture is based on connections (direct or indirect) to existing databases, which supply data on the chemical properties that may be needed for the calculation of the characterisation factors using the OMNIITOX models. In the front end, a user-interface facilitating the handling of data, results, and accompanying information make the information system a user-friendly tool for the LCA practitioner.

\section{Present Status and Outlook}

The accompanying papers are the first scientific articles to be published from this project. Information is also available on the OMNIITOX web site <http://www.omniitox.net>.

The OMNIITOX-project will be finished in November 2004. The parallel work with case studies, the LCIA model construction and the information system development have proven to be fruitful and the lessons learnt in the case studies will influence the further design of models and the information system. This is, for instance, the case regarding the data availability, which was highlighted to be a crucial factor during the case studies. A novel hierarchical approach for handling the data availability problem is presented in the paper by Guinée et al. (2004). The model construction is currently in an advanced state, where major parts are finalised and have been the subject for scientific review by external expertise (in December 2003). An advanced test version of the information system is running and a simplified version of the sophisticated base model is under finalisation.

When the project is finished, characterisation factors for use in LCIA will be available for many more substances than found today in most publicly available sources, the relationships between (E)RA and LCIA will be clearer and the web-based information system will support LCIA and (E)RA practitioners. The models and the information system will also open up possibilities for simple comparisons of chemicals, outside the LCIA application, which e.g. can support work with substitution of chemicals by various actors in the supply chain.

In the more distant future, the further development of the OMNIITOX models and information system, in drawing on a proposed information system supporting the suggested new chemicals legislation, might further increase the number of substances for which characterisation factors are readily available and, hence, facilitate the work towards more comprehensive integration of chemical impacts in LCIA in support of more sustainable provision and use of chemicals and products within society. 


\section{Acknowledgements. The authors gratefully acknowledge the contri-} butions of

- Tomas Rydberg, at that time at Volvo Technology Corporation now at the Institute of Environment and Sustainability JRC, as one of the initiators of the OMNIITOX project.

- Erwin Saouter and Tom Feijtel, Procter \& Gamble, who played important roles during the early stages of project planning. Gerald Vollmer and Arnd Weyers, European Chemicals Bureau, Institute for Human Health and Consumer Protection JRC, who supplied important inputs during the initial planning of the project. Jan Bresky, Stora Enso Oyi, for the support from his company. the European Commission, DG Research, for financial support.

\section{References}

Aldridge WN (1996): Mechanisms and concepts in toxicology. Taylor \& Francis, London, UK

Allanou R, Hansen BG, van der Bilt Y (1999): Public Availability of Data on EU High Production Volume Chemicals, EUR 18996 EN, European Commission, Joint Research Centre, Institute for Health and Consumer Protection, European Chemicals Bureau, TP 280, Ispra (VA), 21020, Italy

Allen TFH, Hoekstra TW (1992): Toward a unified ecology. Columbia University press, New York, USA

Bare JC, Hofstetter P, Pennington DW, Udo de Haes HA (2002): Life cycle impact assessment workshop summary. Midpoints versus endpoints: The sacrifices and benefits. Int J LCA 5:319-326

BUS (1984): Ökobilanzen von Packstoffen. Bundesamt für Umveltschutz, Schriftenreihe Umveltschutz, no. 24 (Bern, Schweiz)

BUWAL (1990): Methodik für Ökobilanzen auf der Basis ökologischer Optimierung. Schriftenreihe Umwelt, no. 133, Abfälle, Bundesamt für Umwelt, Wald \& Landschaft (Bern, Schweiz)

Carlson R, Erixon M, Pålsson A-C, Tivander J (2004): OMNIITOX concept model supports characterisation modelling for life cycle impact assessment. Int J LCA 9 (5) 289-294

CEC (Commission of the European Community) 1996. EUSES, the European Union System for Evaluation of Substances. National Institute of Public Health and the Environment (RIVM), the Netherlands. Available from the European Chemicals Bureau (JRC), Ispra, Italy

CEC (Commission of the European Communities) 1999. Establishing the Ecological Criteria for the award of the Community Eco-label to Laundry Detergents (1999/476/EC), Official Journal of the European Communities L187/52-68, Brussels, Belgium, 20.07.1999

CEC (Commission of the European Community) (2001): White paper: Strategy for a Future Chemicals Policy. COM (2001) 88 final (Brussels, Belgium)

CEC (Commission of the European Community) (2003a): Communication from the Commission to the Council and the European Parliament Integrated Product Policy - Building on Environmental Life-Cycle Thinking. $\operatorname{COM}(2003)$ final (Brussels, Belgium)

CEC (Commission of the European Community) (2003b): Technical Guidance Document on Risk Assessment in support of Commission Directive 93/67/EEC on Risk Assessment for new notified substances, Commission Regulation (EC) No 1488/94 on Risk Assessment for existing substances, Directive 98/8/EC of the European Parliament and of the Council concerning the placing of biocidal products on the market. Institute for Health and Consumer Protection, European Chemicals Bureau

Commission directive 93/67/EEC of 20 July 1993 laying down the principles for assessment of risks to man and the environment of substances notified in accordance with Council Directive 67/548/EEC

Commission regulation (EC) No $1488 / 94$ of 28 June 1994 laying down the principles for risk assessment to man and the environment of existing substances in accordance with Council Regulation (EEC) No 793/93

Council Directive 67/548/EEC on the approximation of laws, regulations and administrative provisions relating to the classification, packaging and labelling of dangerous substances. Official Journal B 196, 16/08/1967

Council Directive 92/32/EEC of 30 April 1992 amending for the seventh time Directive $67 / 548 / \mathrm{EEC}$ on the approximation of the laws, regulations and administrative provisions relating to the classification, packaging and labelling of dangerous substances. Official Journal L 154, 05/06/1992

Council Regulation (EEC) 793/93 of 23 March 1993 on the evaluation and control of the risk of existing substances. Official Journal L 84, 5.4.1993

Christensen FM, Olsen SI (2004): The potential role of life cycle assessment in regulation of chemicals in the European Union. Int J LCA 9 (5) 327-332
Davis G, Fort D, Hansen BG, Irwin F, Jones B, Jones S, Socha A, Wilson R, Haaf B, Gray G, Hoffman B (1997): Framework for Chemical Ranking and Scoring Systems. Chapter 1 in: Chemical ranking and scoring: Guidelines for relative assessment of chemicals, Swanson MB, Socha AC (eds.), pp 1-29. SETAC-US. Proceedings from the Pellston workshop on Chemical ranking and scoring, 12-16 February, 1995 (Sandestin, Florida)

Erixon M, Carlson R, Flemström K, Pålsson AC (2004): The data quality foundation in OMNIITOX information system. Int J LCA 9 (5) 333

Goedkoop, M. \& R. Spriensma, 1999. The Eco-indicator 99. A damage oriented method for life cycle Impact assessment. PRé Consultants, Amersfoort

Guinée JB, Gorrée M, Heijungs R, Huppes G, Kleijn R, de Koning A, van Oers L, Wegener Sleeswijk A, Sub S, Udo de Haes HA, de Bruijn H, van Duin R, Huijbregts MAJ (2002): Handbook on Life Cycle Assessment. Operational Guide to the ISO Standards. Kluwer Academic Publishers, Dordrecht, 2002, xii + 692 pp

Guinée JB, de Koning A, Pennington DW, Rosenbaum R, Hauschild M, Olsen SI, Molander S, Bachmann TM, Pant R (2004): Bringing science and pragmatism together in a tiered approach for modelling toxicological impacts in LCA. Int J LCA 9 (5) 320-326

Hauschild M, Wenzel H (1998): Environmental Assessment of products. Volume 2: Scientific background. Chapman \& Hall, London

Hertwich EG, Hammitt JK (2001): A Decision-Analytic Framework for Impact Assessment. Part II: Midpoints, Endpoints, and Criteria for Method Development. Int J LCA 6 (5) 265-272

Huijbregts MAJ (1999): Priority assessment of toxic substances in LCA. Development and application of the multi-media fate, exposure and effect model USES-LCA. IVAM environmental research, University of Amsterdam, Amsterdam

ISO 14040 (1997): Environmental management - Life Cycle Assessment Principles and Framework

ISO14041 (1998): Environmental management - Life Cycle Assessment Goal and scope definition and inventory analysis

ISO 14042 (2000): Environmental management - Life Cycle Assessment Life cycle impact assessment

ISO/TS 14048 (2002): Environmental management - Life Cycle Assessment - Data documentation format

Jolliet O, Margni M, Charles R, Humbert S, Payet J, Rebitzer G, Rosenbaum R (2003): IMPACT 2002+: A new life cycle impact assessment methodology. Int J LCA 8 (6) 324-330

Larsen HF, Birkved M, Hauschild M, Pennington DW, Guinée JB (2004): Evaluation of selection methods for toxicological impacts in LCA: Recommendations for OMINIITOX. Int J LCA 9 (5) 307-319

Levin SA, Harwell MA, Kelly JR, Kimball KD (eds.) (1989): Ecotoxicology - Problems and approaches. Springer-Verlag, New York, USA. Esp. chapters 3-6

Lidholm P, Boström S, Gunnarsson C, Rydberg T (2002): Vehicle industry case study - Preliminary results. Platform presentation at SETAC Europe annual conference Vienna, May 2002 (available at http://www. omniitox.net/Results/SETAC \%2002/Setac final Peter.pdf)

Molander S (2002): Refined Problem Definition for the OMNITTOX project. Report to the OMNIITOX-project deliverable D8 final, with contributions of Veronica Borghi and Pere Fullana, November 2002, Environmental Systems Analysis, Chalmers University of Technology (Göteborg, Sweden)

Newman MC (1998): Fundamentals of Ecotoxicology. Ann Arbor Press, Chelsea, Michigan, USA, p 213

Pant R, Van Hoof G, Schowanek D, Feijtel TCJ, de Koning A, Hauschild M, Pennington DW, Olsen SI, Rosenbaum R (2004): Comparison between 3 different LCIA methods for aquatic ecotoxicity and a product environmental risk assessment - Insights from a detergent case study within OMNIITOX. Int J LCA 9 (5) 295-306

Peterson DL, Parker VT (eds) (1998): Ecological scale: Theory and applications, Columbia University Press, New York, USA

Saouter E, Feijtel TCJ (2000): Use of Life Cycle Analysis and Environmental Risk Assessment in an Integrated Product Assessment. Environmental Strategies. Nordic Workshop, Vedbaek 1999, ISBN 92-893-0464-2. In: Hauschild M, Olsen SI, Poll C, Bro-Rasmussen F (eds 2000): Risk Assessment and Life Cycle Assessment, TemaNord 2000:545. Nordic Council of Ministers, Copenhagen, 81-97

Udo de Haes H, Jolliet O, Finnveden G, Goedkoop M, Hauschild M, Hertwic E, Hofstetter P, Klöpffer W, Krewitt W, Lindejer E, Mueller-Wenk R, Olson S, Pennington D, Potting J, Steen B (2002): Life-cycle impact assessment: Striving towards best practice. SETAC Press, Pensacola, Florida, USA

Received: October 17th, 2003

Accepted: August 20th, 2004

OnlineFirst: August 20th, 2004 